\title{
A ECONOMIA DE ENERGIA ELÉTRICA NA ILUMINAÇÃO PÚBLICA COM O USO DE LÂMPADAS LED: ESTUDO DE CASO DA AVENIDA RECIFE
}

\author{
LA ECONOMÍA ELÉCTRICA EN EL ALUMBRADO PÚBLICO CON EL USO DE \\ LÁMPARAS LED: CASO DE ESTUDIO AVENIDA RECIFE
}

\section{THE ECONOMY OF ELECTRICAL ENERGY IN PUBLIC LIGHTING WITH THE USE OF LED LAMPS: A CASE STUDY OF AVENIDA RECIFE}

\author{
José Pereira Cavalcanti Filho' \\ José Antônio Aleixo da Silva ${ }^{2}$ \\ Sérgio da Silva Leal ${ }^{3}$
}

RESUMO: Este artigo expõe dados da iluminação pública usada em uma avenida de Recife, Pernambuco. Buscou determinar indicadores de economia de energia e impacto ambiental das tecnologias de iluminação a Light Emitting Diode (LED) em uso relacionada com a vapor de sódio usada anteriormente. Observou-se o gasto com energia elétrica e a quantificação dos resíduos. O estudo de caso foi realizado num trecho de $8 \mathrm{~km}$ e destacou a importância de atender as normas legais vigentes. Demonstrou-se que, no mesmo período, gastou-se 2,27 vezes menos lâmpadas e os resíduos caíram $64 \%$. Economizou-se: energia (282.852 kWh), nos gastos anuais $(\mathrm{R} \$ 130.111,76)$, representando uma redução de $38,47 \%$. Os dados analisados neste trabalho indicam que a iluminação LED é a tecnologia mais apropriada, no momento, para a redução de gastos e a preservação do meio ambiente.

Palavras-chave: Iluminação pública LED. Economia e consumo de energia. Resíduos.

RESUMEN: Este artículo expone datos del alumbrado público utilizado en una avenida en Recife, Pernambuco. Se buscó determinar indicadores de ahorro de energía e impacto ambiental de las tecnologías de iluminación que utilizan diodos emisores de luz (LED) en uso relacionados con el vapor de sodio utilizado anteriormente. Se observaron el gasto eléctrico y la cuantificación de residuos. El estudio de caso se llevó a cabo en un tramo de 8 $\mathrm{km}$ y destacó la importancia de cumplir con los estándares legales actuales. Se demostró que,

\footnotetext{
I Instituto Federal de Educação, Ciência e Tecnologia de Pernambuco/ Departamento Professor do Curso de Eletrotécnica do IFPE. Mestre em Tecnologia Ambiental pelo Instituto de Tecnologia de Pernambuco (ITEP), Recife - PE. https://orcid.org/oooo-oooz-4762-7631. Acadêmico de Cursos Técnicos (IFPE/DACT). Licenciatura Plena em Eletricidade, Centro Federal de Educação Tecnológica de Minas Gerais (CEFET/MG).E-mail: josepereira@recife.ifpe.edu.br.

${ }_{2}^{2}$ PD em Biometria e Manejo Florestal pela University of Georgia, USA. Prof. Titular do DCFL/UFRPE, $\mathrm{PhD}$ em Biometria e Manejo Florestal. Ex-Presidente da Academia Pernambucana de Ciências - APC. Conselheiro da Sociedade Brasileira para o Progresso da Ciência - SBPC. https://orcid.org/oooo-0oo3-06753524. Agronomia, UFRPE, E-mail: jaaleixo@uol.com.br.

3 Doutor em Tecnologias Energéticas e Nucleares pela Universidade Federal de Pernambuco (UFPE) Recife PE. Professor do Curso de Eletrotécnica do IFPE.https://orcid.org/oooo-ooo2-o615-8314. Engenharia Eletrônica pela Universidade de Pernambuco (UPE). E-mail: sergio-lealifpe@hotmail.com
} 
en el mismo período, se utilizaron 2,27 veces menos lámparas y los residuos se redujeron en un $64 \%$. Se obtuvieron ahorros: energía $(282.852 \mathrm{kWh}$ ), en gastos anuales ( $\mathrm{R} \$ 130.111,76)$, lo que representa una reducción del $38,47 \%$. Los datos analizados en este trabajo indican que la iluminación LED es la tecnología más adecuada, en este momento, para reducir costes y preservar el medio ambiente.

Palabras clave: Alumbrado público LED. Ahorro y consumo energético. Residuos.

ABSTRACT: This article exposes data from public lighting used on an avenue in Recife, Pernambuco. It sought to determine indicators of energy savings and environmental impact of lighting technologies using Light Emitting Diode (LED) in use related to the sodium vapor used previously. Electricity expenditure and waste quantification were observed. The case study was carried out over an $8 \mathrm{~km}$ stretch and highlighted the importance of meeting current legal standards. It was shown that, in the same period, 2.27 times fewer lamps were used and waste fell by $64 \%$. Savings were made: energy $(282,852 \mathrm{kWh})$, in annual expenses

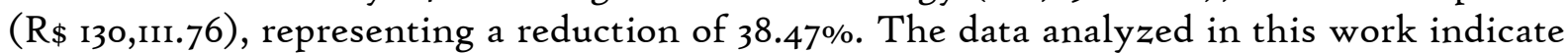
that LED lighting is the most appropriate technology, at the moment, to reduce costs and preserve the environment.

Keywords: Public lighting LED. Energy savings and consumption. Waste.

\section{INTRODUÇÃO}

A demanda global de energia em 2017 aumentou 2,1\%, em comparação com o,9\% no ano anterior e $0,9 \%$ em média nos cinco anos anteriores. Mais de $40 \%$ do crescimento em 2017 foi impulsionado pela China e pela Índia; 72\% do aumento foi atingido por combustíveis fósseis, um quarto por energias renováveis e o restante por energia nuclear. Quanto às emissões globais de $\mathrm{CO}_{2}$ em 2017 relacionadas à energia cresceram $\mathrm{I}, 4 \%$, atingindo uma alta histórica de 32,5 gigatoneladas $(\mathrm{Gt})$, uma retomada do crescimento após três anos de emissões globais remanescentes. $\mathrm{O}$ aumento das emissões de $\mathrm{CO}_{2}$, no entanto, não foi universal. Enquanto na maioria das grandes economias emissões de $\mathrm{CO}_{2}$ aumentaram, outras experimentaram declínios, incluindo Estados Unidos, Reino Unido, México e Japão. O maior declínio ocorreu nos Estados Unidos, principalmente devido à maior implantação de energias renováveis. (INTERNATIONAL ENERGY AGENCY, 2017).

Paralelamente, conforme o Banco Mundial, a perversa máquina de acumulação de riqueza e capital, cujo funcionamento está baseado em um modelo de extração, produção e descarte provocará a elevação do volume global de descarte de lixo e de resíduos sólidos em cerca de $70 \%$ até 2050, quando se alcançará 3,4 bilhões de toneladas, frente a 2,or bilhões de 2016. (ALVES, 2018). 
A saúde do ser humano, dos demais seres vivos e do meio ambiente, assim como agravamento das mudanças climáticas terão como uma ameaça adicional, de maneira óbvia, o aumento e a multiplicação de lixo e resíduos no mundo. (KAZA, et al., 2018).

$\mathrm{Na}$ realidade atual se convive com um quadro preocupante no país e no planeta, devido ao aumento desenfreado do consumo em geral, onde se inclui o setor elétrico, que gera um aumento relevante de lixo, que tem a capacidade de impactar negativamente no meio ambiente e interferir da mesma forma nos ecossistemas da natureza.

Em 2018 ocorreu o maior crescimento anual da última década na demanda mundial de energia, verificando-se um aumento de $2,3 \%$. A população mundial sem eletricidade caiu para menos de um bilhão pela primeira vez. Grandes expectativas são proporcionadas pelo uso da energia elétrica, porém há dúvida quanto à sua capacidade de suprir aos diversos tipos de demanda e como operarão os sistemas elétricos futuros. (AIE, 2019).

Conforme informação da Empresa de Pesquisa Energética (EPE) do Ministério de Minas e Energia relativamente ao ano de 2017, o consumo da iluminação pública no Brasil correspondeu a 3,3\% do consumo total de energia elétrica do País, que foi de 467.16r GWh, destacando-se o consumo industrial em primeiro lugar com $35,8 \%$, o consumo residencial em segundo lugar com $28,8 \%$ e o consumo com iluminação pública em quinto lugar com 3,3\%, conforme está representado na Figura I. (BRASIL, 20I8a).

Figura I - Indicadores percentuais do consumo de energia elétrica dos consumidores do Brasil em 2017

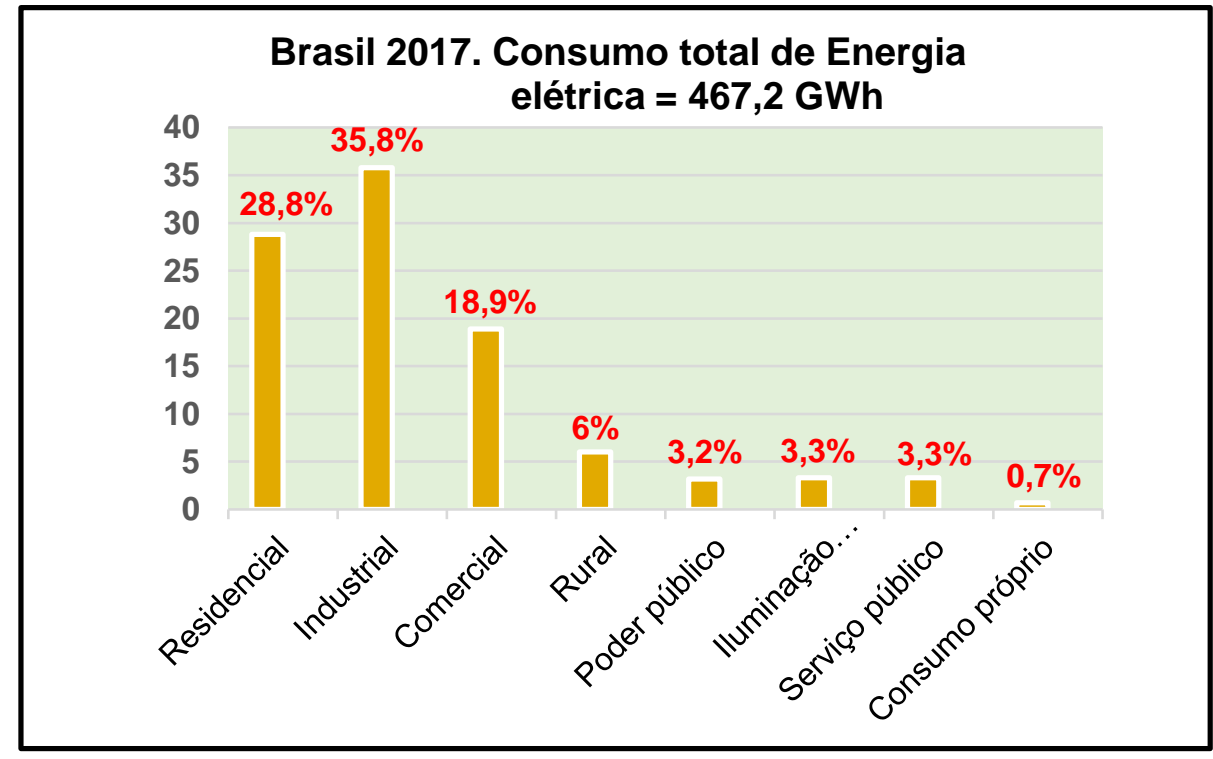

Fonte: elaborado pelo autor, (2019). 
O gasto de energia elétrica na iluminação pública (IP) e os impactos ambientais consequentes das tecnologias usadas são problemas preocupantes atualmente. Uma cidade para funcionar bem terá como necessidade básica uma iluminação pública adequada, a qual é essencial para a melhoria da qualidade de vida da população, possibilitando a identificação das áreas públicas, desenvolvimento local e dos caminhos de deslocamento noturno com segurança.

(PIRES, 2017).

Para Aguilar (2015), com o aumento desordenado do crescimento urbano das cidades brasileira, atualmente o lixo gerado tem sido uma grande preocupação, destacando-se o produzido pelo descarte de resíduos sólidos, tais como lâmpadas, pilhas e baterias.

Conforme menciona Gusmão (2017), o limite da quantidade de mercúrio para as lâmpadas não é estabelecido por legislação brasileira e praticamente a maior parte das empresas do setor de fabricação de lâmpadas tornaram-se importadoras. Afirma que com a logística reversa, por facilitar a separação dos materiais e elevar o índice de reciclagem no país, ocorrerá redução do volume descartado de resíduos e menos agressão ao meio ambiente.

A pesquisa realizada por Santos R. et al. (2017), destaca os riscos oferecidos pelo 4 manuseio incorreto das lâmpadas a vapor, ao meio ambiente e à saúde física dos profissionais da área, a importância da conscientização dos riscos que existem com as lâmpadas a vapor, e para uso das medidas de segurança que sirvam de referência em empresas e residências. Neste sentido, enfocam quais as responsabilidades que devem ter a sociedade e as empresas pelas medidas tomadas. Além disto mencionam que o manuseio e o descarte de lâmpadas a vapor, por aumentar de forma exponencial, concorrerá para prejudicar a saúde humana e seus resíduos causar grandes danos ao meio ambiente.

Pelo disposto na Lei Federal no 12.305 , sancionada em 02 de agosto de 2010, que instituiu a Política Nacional de Resíduos Sólidos, destaca dentre outros pontos, os referentes a gestão, gerenciamento de resíduos sólidos, incluídos os perigosos, as responsabilizações, aplicabilidade e ainda menciona no artigo 33, incisos V e VI que:

\footnotetext{
Art. 33. São obrigados a estruturar e implementar sistemas de logística reversa, mediante retorno dos produtos após o uso pelo consumidor, de forma independente do serviço público de limpeza urbana e de manejo dos resíduos sólidos, os fabricantes, importadores, distribuidores e comerciantes de:

V - lâmpadas fluorescentes, de vapor de sódio e mercúrio e de luz mista;

VI - produtos eletroeletrônicos e seus componentes. (BRASIL, 2010).
} 
Em um panorama nacional é mencionado pela Associação Brasileira das Concessionárias Privadas de Serviços de Iluminação Pública (ABCIP) que o parque de iluminação pública do Brasil tem aproximadamente 16 milhões de pontos, proporcionando um gasto com energia elétrica estimado de $\mathrm{R} \$ \mathrm{I}, 5$ bilhão anual. (ABCIP, 2020).

$\mathrm{Na}$ iluminação pública a eficiência energética concernente às lâmpadas nela usada, dependerá da eficiência delas quanto ao consumo de energia elétrica, custo-benefício, vida útil, aparência de cor, eficiência luminosa e fluxo luminoso. Convém acrescentar que havendo o emprego de tecnologias eficientes é possível diminuir a demanda em horários de ponta e reduzir a perda de energia elétrica com uma melhor qualidade de serviços prestados. (KRUGER; RAMOS, 2016).

Com a crescente necessidade de uso eficiente da energia elétrica e devido aos impactos ambientais precisos para sua obtenção, surgiram ações e programas em prol da redução de custos e de limitar o consumo de energia. (PINTO; KIRCHNER, 2016).

No Brasil, o Programa Nacional de Conservação de Energia Elétrica (PROCEL) criado em 1985 pelo Ministério de Minas e Energia possibilitou, em 2017, a economia de 21,2 bilhão de $\mathrm{kWh}$, o que significa 4,5\% do consumo total de eletricidade nacional do ano citado e reduziu a emissão de 1,965 milhão de $\mathrm{tCO}_{2}$ equivalentes na atmosfera, devido ao uso mais eficiente da energia. Associado ao PROCEL o Governo Federal em 2000 cria o Programa Nacional de Iluminação Pública e Sinalização Semafórica Eficientes (RELUZ) que já possibilitou a troca de mais de 2,7 milhões de pontos de iluminação pública em todo o País, concorrendo para elevar a segurança e qualidade de vida nas cidades brasileiras. (PROCEL, 2018).

Em 3 de maio de 2016, foi sancionada pela presidência da república a Lei no 13.280/2016, para melhorar a utilização dos recursos direcionados aos programas de eficiência energética. Com isto, o PROCEL RELUZ, assumiu uma nova etapa perante a qual focaliza a promoção da iluminação pública a LED, como a tecnologia mais eficiente e durável que as anteriores. (BRASIL, 20I6b).

Para eficientizar a iluminação BERGSTRÖM, L. et al. (2014), destacam a importância para a humanidade da descoberta dos ganhadores do Prêmio Nobel de Física de 2014, os pesquisadores e professores japoneses Shuji Nakamura, Hiroshi Amano e Isamu Akasaki, a qual, revolucionou a tecnologia da iluminação com a produção de novas lâmpadas mais 
baratas, eficientes, as lâmpadas LED brancas. Tendo a possibilidade controlar a cor da luz e sendo a grande esperança de melhoras da qualidade de vida de mais de 1,5 bilhão de pessoas que no momento não usam redes elétricas, as lâmpadas LED podem ser alimentadas por energia solar.

Atinente a iluminação pública três fases distintas são observadas: a primeira focada principalmente na segurança que perdurou até o invento da energia elétrica; a segunda de simplesmente iluminar e centrada no trânsito de veículos sendo do final do século XIX até I980; e a terceira de valorizar, melhorar o marketing e de criação de identificação, das paisagens, espaços urbanos das cidades, que teve início no término do século $\mathrm{XX}$. (SANTOS, E. R., 2005).

A Prefeitura do Recife em 1998, pelo Convênio com o PROCEL (Eletrobrás) e a Companhia Hidroelétrica do São Francisco (CHESF), assinalou significativamente a história da iluminação pública da Capital, com a troca da iluminação a vapor de mercúrio por lâmpadas a vapor de sódio, que elevam os índices de iluminação, de durabilidade média e diminuem os gastos de energia elétrica nas vias públicas da cidade, (Figura 2). Cronologicamente do século XIX até o atual a iluminação pública do Recife mudou conforme apresentado no Quadror.

Figura 2 - Tipos de iluminação elétrica e durabilidade.

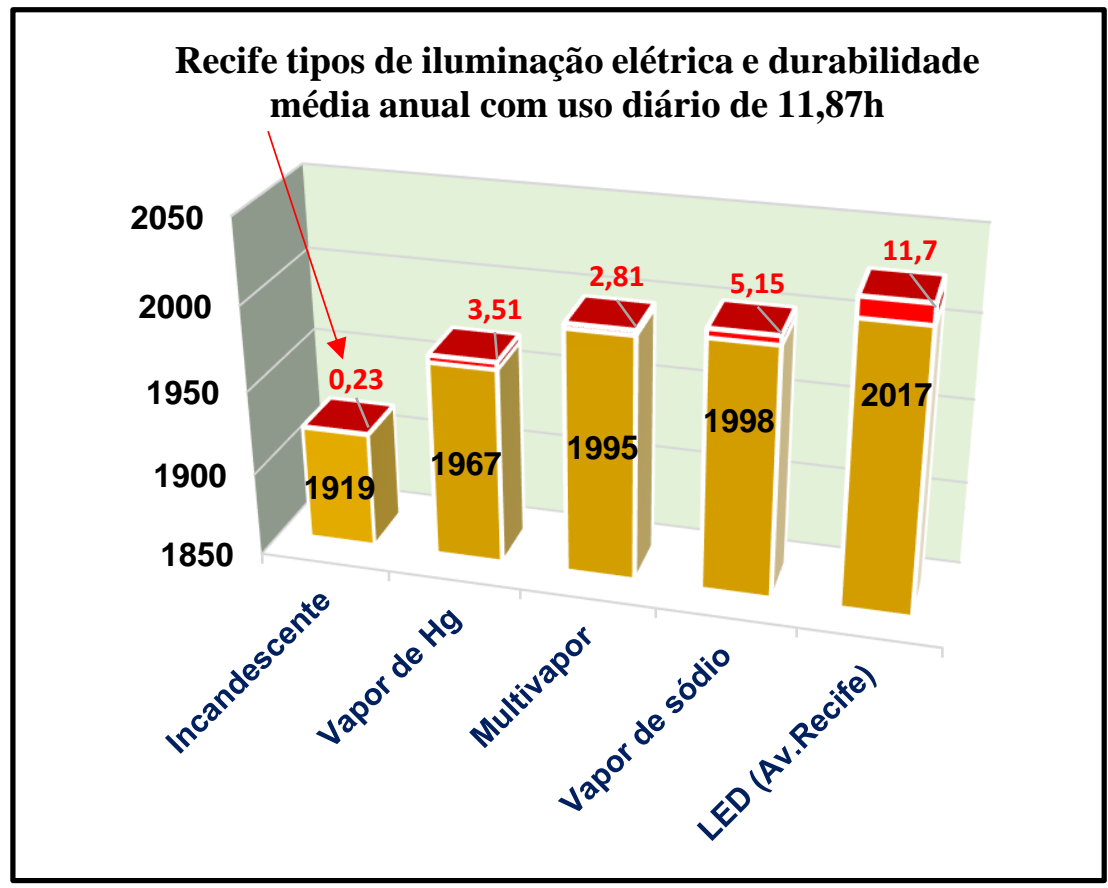

Fonte: elaborado pelo autor, (2019). 
Quadro I - Evolução cronológica da iluminação do Recife/ Pernambuco.

Fonte: adaptado de PIRES, (2017).

\begin{tabular}{|c|l|}
\hline Ano & \multicolumn{1}{|c|}{ Evento } \\
\hline I822 & $\begin{array}{l}\text { Iniciou iluminação pública do Recife com a inauguração dos primeiros } \\
\text { lampiões de azeite de mamona e óleo de peixe }\end{array}$ \\
\hline I859 & Foram implantados os lampiões a gás carbônico \\
\hline I919 & Houve a instalação da luz elétrica com lâmpadas incandescentes \\
\hline 1967 & As ruas do Recife ganharam um sistema de iluminação a vapor de mercúrio \\
\hline I970 & $\begin{array}{l}\text { Os pontos de luz passam a ter controles por relés fotoelétricos, terminando as } \\
\text { atividades das equipes que diariamente percorriam as ruas acendendo e } \\
\text { apagando as lâmpadas, ao anoitecer e ao amanhecer }\end{array}$ \\
\hline I995 & $\begin{array}{l}\text { A Avenida Boa Viagem inicia a iluminação com lâmpadas multivapor } \\
\text { metálico }\end{array}$ \\
\hline 1998 & Troca da iluminação a vapor de mercúrio por lâmpadas a vapor de sódio \\
\hline 2017 & A Avenida Recife inicia a iluminação com luminárias LED \\
\hline
\end{tabular}

Segundo a Agência Nacional de Energia Elétrica (ANEEL) de acordo com o artigo 218, da RESOLUÇÃO NORMATIVA (REN) 4I4/2010, o sistema de iluminação deve ser transferido da distribuidora para a pessoa jurídica de direito público competente, (ANEEL, 2010).

Quanto ao pagamento da iluminação pública, segundo a Constituição da República Federativa do Brasil de 1988, nos Artigos 30 e 149 A são destacados a atribuição dos serviços públicos de interesse da localidade para o município e responsabilidade competência do custeio do serviço de iluminação pública para o município e Distrito Federal. (BRASIL, [2016] a).

Atinente ao Custeio da Iluminação Pública (CIP) é verificado com a regulamentação dos métodos e responsabilização tributária da empresa concessionária do serviço público de distribuição de energia elétrica, pelo prefeito da cidade do Recife, que no uso de sua responsabilidade e conforme estabelecido no Artigo 70-A da lei no ${ }_{15.563}$, homologa um decreto para esse propósito. O Decreto $\mathrm{n}^{\mathrm{0}} 28.77 \mathrm{I}$ de 27 de abril de 2015, que menciona:

Art. Io . A empresa concessionária do serviço público de distribuição de energia elétrica, como responsável tributária, deverá cobrar a Contribuição para Custeio da Iluminação Pública (CIP) dos contribuintes com faturamento ativo, juntamente com a fatura mensal de consumo, nos mesmos prazos e sistemáticas por ela utilizados.

Art. 2ㅇ․ O valor da CIP será incluído no montante total da fatura mensal de energia elétrica emitida pela concessionária, e será calculada de conformidade com as seguintes Tabelas: 
As tabelas mencionadas no Decreto são duas denominadas de "Consumidor Residencial" e a outra de "Consumidor Comercial, Industrial e Outros", as quais resultaram na Tabela I, elaborada com os dados das duas tabelas. O Decreto, que ainda define, no parágrafo I을 do artigo $2^{2}$, a Tarifa Convencional de Iluminação Pública (TCIP), no valor de ıo $\mathrm{kWh}$ vigente para iluminação pública. (RECIFE, 2015).

Tabela I - Valor da TCIP do consumidor considerando o consumo mensal.

\begin{tabular}{|c|c|c|c|c|}
\hline \multirow[b]{2}{*}{ Faixa } & \multicolumn{2}{|c|}{ Residencial } & \multicolumn{2}{|c|}{ Comercial, industrial e outros } \\
\hline & Consumo kWh & $\begin{array}{c}\text { Valor em } \\
\text { TCIP }\end{array}$ & Consumo $\mathrm{kWh}$ & $\begin{array}{c}\text { Valor em } \\
\text { TCIP }\end{array}$ \\
\hline I & Até 8o & 0,00 & Até 30 & 0,00 \\
\hline 2 & 8I a Ioo & 2,26 & 31 a 80 & 2,64 \\
\hline 3 & IOI a I5O & 3,43 & 8 I a IOo & 3,43 \\
\hline 4 & I5I a 300 & 4,45 & IOI a I5O & 4,45 \\
\hline 5 & 301 a 500 & 5,78 & I5I a 300 & 5,78 \\
\hline 6 & 501 a 750 & 7,16 & 301 a 500 & 7,52 \\
\hline 7 & 751 a 1.000 & 8,29 & 501 a 1.000 & 9,78 \\
\hline 8 & IOOI a I5O0 & 9,04 & Acima de I.ooo & $\mathrm{I} 2,7 \mathrm{I}$ \\
\hline 9 & Mais de 1500 & 9,87 & & \\
\hline
\end{tabular}

Fonte: adaptado de RECIFE, (2015).

Para a obtenção do consumo de energia elétrica em $\mathrm{kWh}$ é necessário, além da potência total em $\mathrm{kW}$, estabelecer o tempo de utilização dos pontos de consumo em horas compatibilizados com essa necessidade. Em atendimento a este propósito e para a iluminação pública, segundo a Agência Nacional de Energia Elétrica (ANEEL), é mencionado que:

Para fins de faturamento da energia elétrica destinada à iluminação pública ou à iluminação de vias internas de condomínios, o tempo a ser considerado para consumo diário deve ser de II (onze) horas e 52 (cinquenta e dois) minutos, ressalvado o caso de logradouros que necessitem de iluminação permanente, em que o tempo é de 24 (vinte e quatro) horas por dia do período de fornecimento. (ANEEL, 2010, p.42).

Portanto foi utilizado o tempo diário de in h 52 min que equivale a II 87 h. Quanto a determinação do gasto de energia elétrica, o custo unitário do $\mathrm{kWh}$ em $\mathrm{R} \$$, obtido com valor da TCIP na Tabela r e sendo uma TCIP correspondente a io $\mathrm{kWh}$ vigente para iluminação pública. (RECIFE, 2015). 
Este trabalho teve como objetivo, avaliar como a tecnologia da iluminação LED contribui para a preservação do meio ambiente, devido a redução de emissão de $\mathrm{CO}_{2}$ e na redução do percentual de consumo de energia elétrica na iluminação pública em Recife, Pernambuco.

É mencionado por Dantas, Apolônio e Junior (2019) que, conforme a metodologia Bottom-up do Painel Intergovernamental de Mudanças Climáticas (IPCC), consegue-se medir as emissões de $\mathrm{CO}_{2}$ originadas da geração de energia elétrica consumida. A medição do nível de emissão de $\mathrm{CO}_{2}$ da unidade consumidora será feita pela Equação I, ajustada do manual de diretrizes para inventário nacional de Gases de Efeito Estufa (GEE) do IPCC (2006).

$$
\mathrm{E} \mathrm{CO}_{2}=\mathrm{E} \times \mathrm{FE}
$$

Sendo:

$\mathrm{E} \mathrm{CO}_{2}=$ Emissão de GEE $(\mathrm{kg} \mathrm{CO} /$ dia $)$

$\mathrm{E}=$ Consumo de Energia Elétrica $(\mathrm{kWh} / \mathrm{dia})$

$\mathrm{FE}=$ Fator de emissão geração $\mathrm{FV}(\mathrm{kg} \mathrm{CO} / \mathrm{kWh})$

$\mathrm{O}$ fator emissão de $\mathrm{CO}_{2}$ da Equação I, é obtido do relatório mensal do Ministério da

Ciência, Tecnologia, Inovações e Comunicações (MCTIC) do Brasil sendo o consumo de energia elétrica da unidade consumidora originado da concessionária local que esteja interligada ao Sistema Interligado Nacional do Brasil (SIN). O objetivo desse relatório é de mensurar a quantidade de $\mathrm{CO}_{2}$ de emissão do SIN.

A procura permanente por eficiência mais elevada, associada ao emprego adequado de recursos públicos e melhoria do bem-estar nas cidades do Brasil tem sido bastante estudada pela administração do Estado brasileiro. Nesta discussão um dos destaques é para o uso eficiente da energia elétrica, onde se procura conciliar a tendência vista a nível global de ter cada vez mais economia com o gasto energético dos sistemas e equipamentos que necessitam de energia elétrica para funcionar, dentre eles os direcionados para iluminação pública. Neste sentido visando a preservação ambiental e a diminuição dos gastos de energia elétrica, a tecnologia LED surge como a mais recente tendência do setor de iluminação para construções ecologicamente corretas. (FERNANDES; RASOTO, 2017). 


\section{METODOLOGIA}

O estudo de caso da Avenida Recife, em Recife, Pernambuco ocorreu ao longo dos seus aproximadamente $8,0 \mathrm{~km}$ de extensão, onde nos últimos cinco anos, empregou-se para a sua Iluminação Pública a tecnologia de lâmpadas de descarga elétrica de alta pressão. Esta tecnologia de iluminação era utilizada no trecho que abrangia a Avenida Recife, Avenida Presidente Dutra e o viaduto Tancredo Neves. A partir de 2017, começou a ser substituída pela tecnologia de iluminação com luminárias a LED, sendo concluída em 2018. Essa fase de transição é constatada na Figura 3, na qual se visualiza à esquerda a estrutura menor referente a um poste duplo com duas luminárias para LED correspondente ao modelo definido para uso, e à direita a estrutura maior de um poste com luminária dupla para lâmpada a vapor de sódio que era o usado na tecnologia anterior.

A instalação das novas luminárias com seus postes de 9,5m de altura, como também de todos os equipamentos necessários para os novos circuitos foi realizada primeiramente, para logo após, de forma gradativa, serem desinstalados todos os postes com a tecnologia de iluminação anterior. Esta metodologia empregada na realização dos serviços é chamada de Manutenção Não Destrutiva (MND), objetivando interferir o mínimo possível no local onde a obra é realizada e ter o reaproveitamento possível do material dali retirado. (DEZZOTI, 2008 apud GOMES, 2016).

Figura 3 - Avenida Recife durante a mudança das luminárias com lâmpada descarga elétrica para LED.

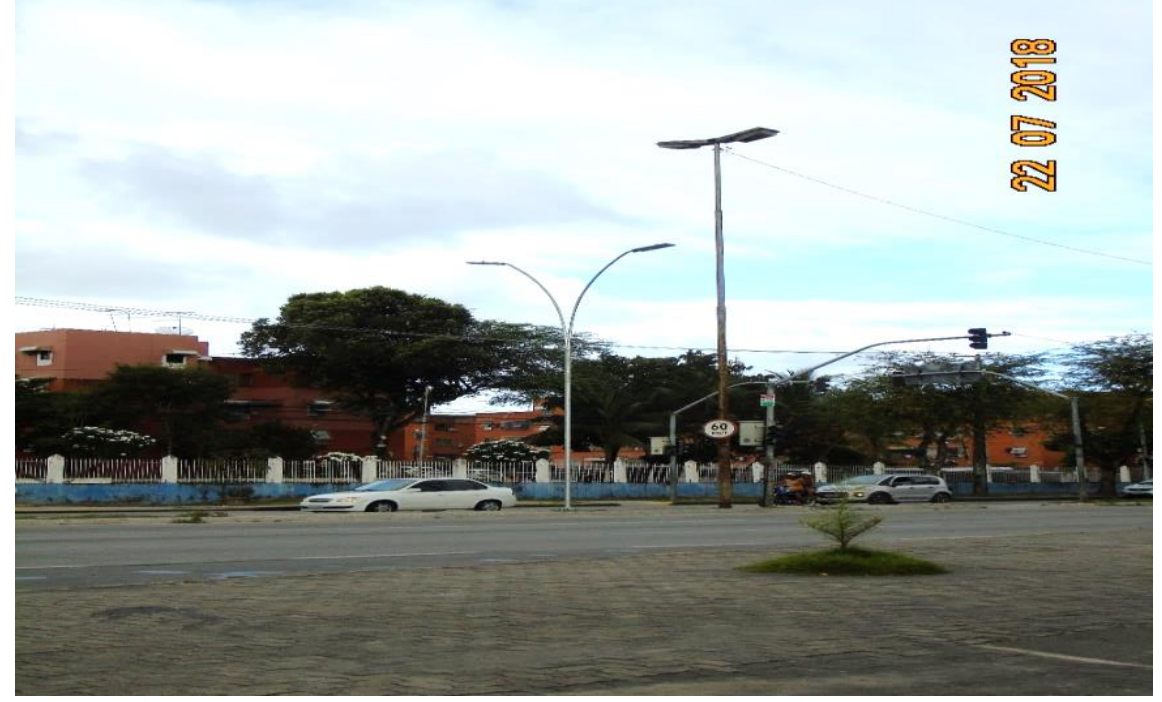

Fonte: elaborado pelo autor, (2018). 
Houve a necessidade de um levantamento de dados os mais precisos e detalhados, necessários a uma análise da economia de energia elétrica, relacionada à iluminação pública, como também, a economia de forma indireta para a sua sustentabilidade. Objetivamente, teve como procedimento as seguintes etapas: $i$ ) levantamento e aquisição de material e dados necessários (cópia do Projeto executado, Constituição Federal do Brasil de 1988, Leis, Normas técnicas, Resoluções, Decretos, Artigos técnicos inter-relacionados e desenhos do trecho total do caso em foco, nas Figuras de 4 a 6, são exibidos os trechos inicial e final);

Figura 4 - Desenho do trecho inicial com dados não visíveis

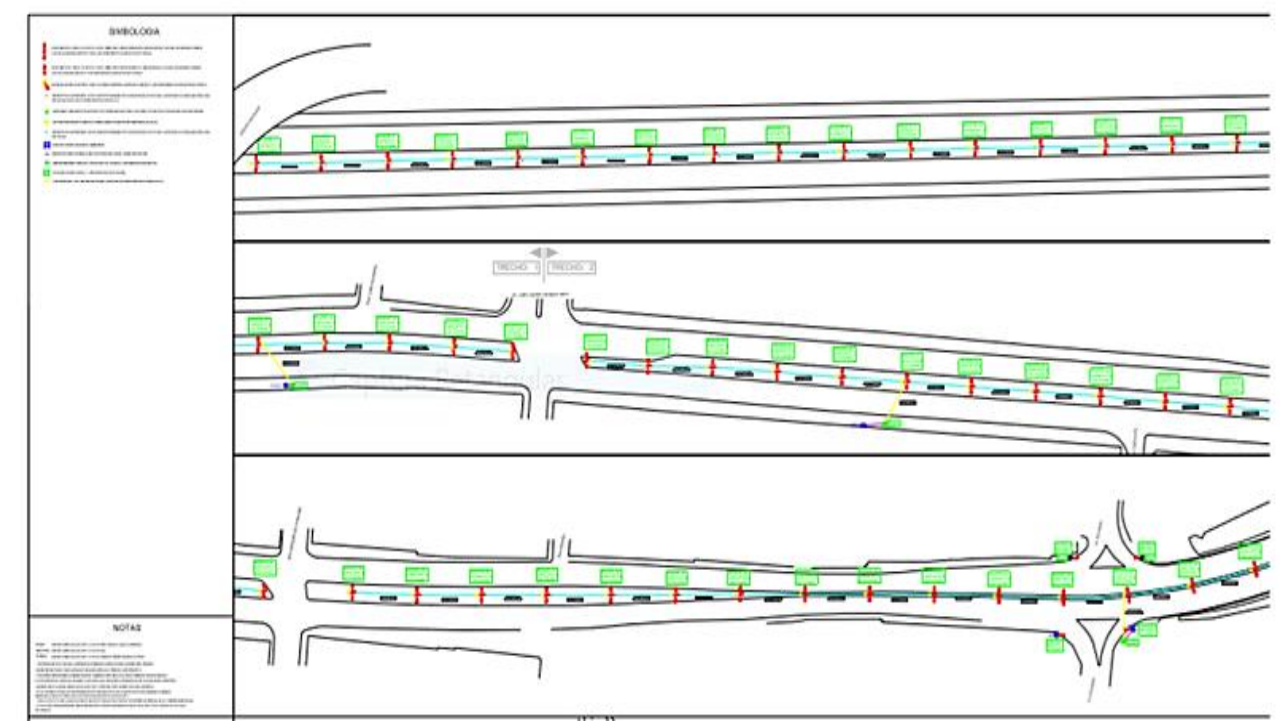

Fonte: EMLURB, (2017).

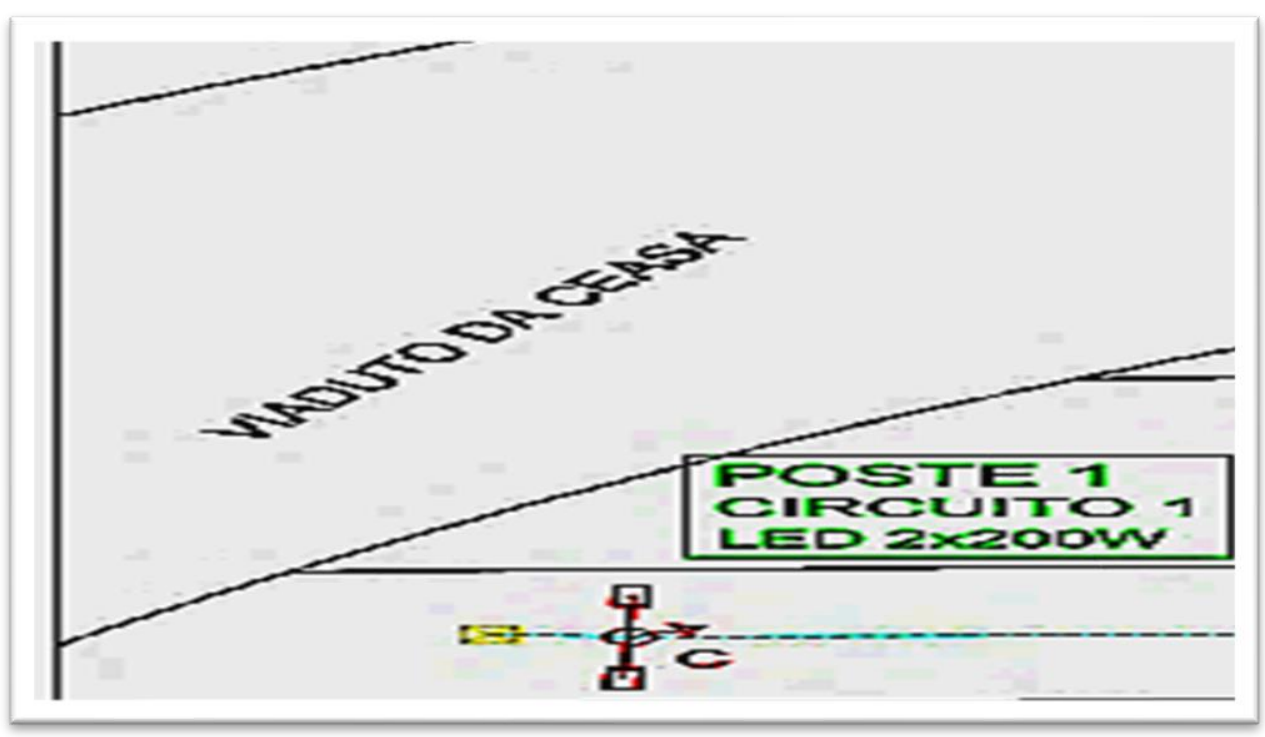

Fonte: EMLURB, (2017). 
Figura 6 - Desenho do trecho final com dados visíveis, em escala adequada.

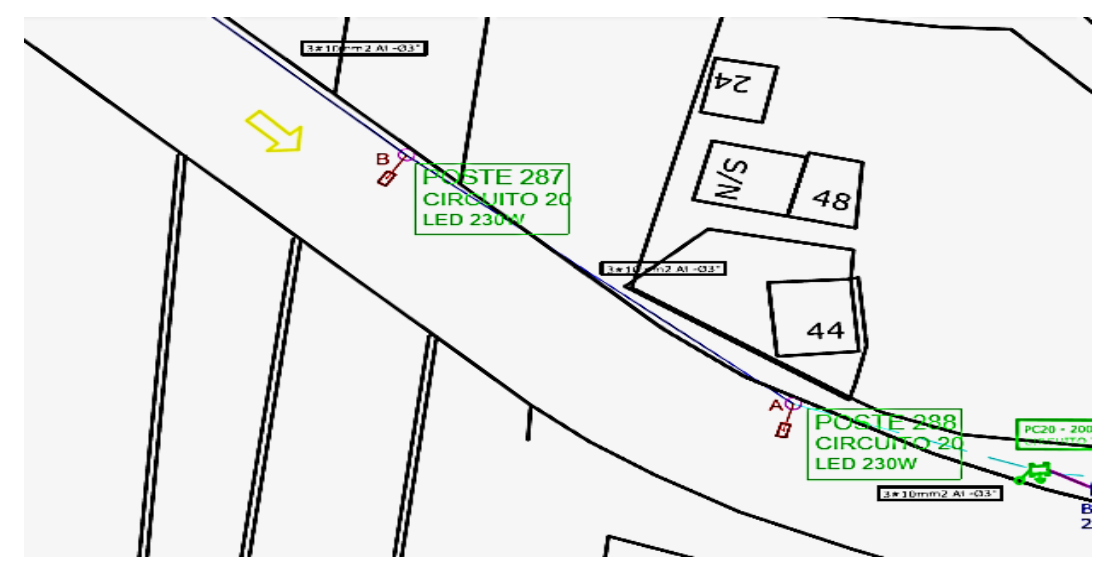

Fonte: EMLURB, (2017).

ii) estudo dos materiais obtidos e inspeção visual durante 3 dias dos 8,o km do local alvo de estudo); iii) tratamento e organização dos dados obtidos para análise posterior, houve a necessidade de adequação dos desenhos (Figuras de 4 a 6), para possibilitar a obtenção dos valores de potência elétrica da tecnologia LED, devido a sua escala original dificultar a visualização e a obtenção das quantidades de circuitos, luminárias com suas respectivas potências e postes; $i v$ ) elaboração de tabelas com dados reais para confirmação e comparação da tecnologia de lâmpada a vapor de sódio (VS) e luminárias LED; v) análises realizadas (do desenho do projeto da tecnologia LED e informação documental da tecnologia anterior e ainda da quantidade de circuitos, postes, luminárias e potência (W), das luminárias, dos circuitos para cada tecnologia).

\section{RESULTADOS E DISCUSSÃO}

Comparando os sistemas de iluminação utilizados, convém mencionar os seguintes detalhamentos característicos, quanto as tecnologias de iluminação usadas na Avenida Recife.

Quanto a tecnologia que foi empregada anteriormente: $i$ ) nas luminárias existiam duas lâmpadas a vapor de sódio de alta pressão de $250 \mathrm{~W}$, com aparência de cor branco amarelado, agradável a visão, alta eficiência e bom índice de reprodução de cores (IRC); postes tinham a altura de $12 \mathrm{~m}$, havia 157 instalados no canteiro central da via e em cada poste a quantidade de 2 luminárias. (EMLURB, 2020); ii) quanto a tecnologia LED usada atualmente, luminária LED com potências de $200 \mathrm{~W}$ ou $230 \mathrm{~W}$, segundo projeto executivo, 
poste das luminárias simples ou duplos, altura $9,5 \mathrm{~m}$, material de fabricação aço SAE Iого/IOzo e tendo um total de 288 postes, segundo visualização no desenho do projeto executivo (EMLURB, 2017).

A totalização da potência elétrica de todos os pontos de consumo instalados de iluminação com a tecnologia LED no local de estudo foi obtida com o somatório das potências de todos os circuitos, do primeiro ao vigésimo circuito exibido no Quadro 2.

Quadro 2 - Totalização da potência elétrica dos pontos de consumo instalados de iluminação LED do estudo de caso.

\begin{tabular}{|c|c|c|c|c|c|}
\hline \multirow{2}{*}{ Circuito $\mathbf{n}^{\circ}$} & \multicolumn{2}{|c|}{ Postes } & \multicolumn{3}{|c|}{ Luminárias } \\
\hline & Numeração & Quantidade & Quantidade & $\mathbf{P i}(\mathbf{W})$ & Pt(W) \\
\hline 1 & 1 até 21 & 21 & 42 & 200 & 8400 \\
\hline 2 & 22 até 33 & 12 & 24 & 200 & 4800 \\
\hline 3 & 34 até 54 & 21 & 42 & 200 & 8400 \\
\hline 4 & 55 até 67 & 13 & 26 & 200 & 5200 \\
\hline 5 & 68 até 86 & 19 & 38 & 200 & 7600 \\
\hline 6 & 87 até 99 & 13 & 26 & 200 & 5200 \\
\hline 7 & 100 até 115 & 16 & 32 & 200 & 6400 \\
\hline 8 & 116 até 131 & 16 & 32 & 200 & 6400 \\
\hline 9 & 132 até 148 & 17 & 34 & 200 & 6800 \\
\hline 10 & 149 até 160 & 12 & 24 & 200 & 4800 \\
\hline 11 & 161 até 174 & 14 & 28 & 200 & 5600 \\
\hline 12 & 175 até 187 & 13 & 26 & 200 & 5200 \\
\hline \multirow{2}{*}{13} & 188 até 203 & 16 & 32 & 200 & 6400 \\
\hline & 256 até 268 & 13 & 13 & 230 & 2990 \\
\hline \multirow{5}{*}{14} & 204 até 208 & 5 & 5 & 200 & 1000 \\
\hline & 209 até 212 & 4 & 8 & 200 & 1600 \\
\hline & 213 até 214 & 2 & 2 & 230 & 460 \\
\hline & 215 até 224 & 10 & 10 & 230 & 2300 \\
\hline & 225 até 226 & 2 & 4 & 230 & 920 \\
\hline 15 & 227 até 230 & 4 & 4 & 230 & 920 \\
\hline 16 & 231 até 237 & 7 & 14 & 230 & 3220 \\
\hline 17 & 243 até 245 & 3 & 3 & 230 & 690 \\
\hline \multirow{6}{*}{18} & 238 & 1 & 2 & 230 & 460 \\
\hline & 239 & 1 & 1 & 230 & 230 \\
\hline & 240 & 1 & 2 & 230 & 460 \\
\hline & 241 & 1 & 1 & 230 & 230 \\
\hline & 242 & 1 & 2 & 230 & 460 \\
\hline & 246 até 255 & 10 & 10 & 230 & 2300 \\
\hline \multirow{2}{*}{19} & 269 até 276 & 8 & 16 & 230 & 3680 \\
\hline & 277 até 282 & 6 & 6 & 230 & 1380 \\
\hline 20 & 283 até 288 & 6 & 6 & 230 & 1380 \\
\hline Totais & 288 & 288 & 515 & 0 & 105880 \\
\hline
\end{tabular}

Fonte: elaborado pelo autor, (2019).

O Quadro 2 tem três colunas principais: a primeira coluna com a numeração dos circuitos de I até 20, que são os existentes no desenho do projeto e serviram para identificação dos dados elétricos pertencentes aos mesmos. A segunda coluna referente aos postes, com duas subdivisões: uma com sua faixa de numeração, onde se visualiza um número atribuído a cada poste e a outra com a quantidade de postes. A terceira coluna é a das luminárias, com 
três subdivisões: a primeira para sua quantidade por circuito, a segunda apresenta a potência unitária $(\mathrm{Pi})$, que é o valor de potência de cada luminária em watts e a terceira com a potência total de cada circuito $(\mathrm{Pt})$, na qual se verifica o somatório das potências de todas as luminárias de um mesmo circuito

Concernente ao custo unitário da energia elétrica da iluminação pública em $\mathrm{kWh}$, foi obtido com um consumo de energia residencial da Faixa 4 na Tabela I, que paga atualmente $\mathrm{R}$ \$ 20,58 como Contribuição de Iluminação Pública (CIP) municipal na fatura mensal emitida pela concessionária, conforme se verifica a seguir: i) consumidor da Faixa $4 \rightarrow 4,45$ TCIP (Tabela I); ii) donde se tem que, 4,45 TCIP = R $\$ 20,58 ;$ iii) portanto, $\mathrm{ITCIP}=\mathrm{R} \$ 20,58 /$ 4,45; iv) com isso, I TCIP = R $\$ 4,62 ; v$ ) devido a I TCIP = Io kWh (Decreto no 28.77I); vi) se tem que, Io $\mathrm{kWh}=\mathrm{R} \$ 4,62 ;$ vii) resultado é que, $\mathrm{I} \mathrm{kWh}=\mathrm{R} \$ 0,46$.

Com a aplicação dos dados normativos obtidos, referentes ao tempo de utilização diária para a iluminação pública pela Resolução Normativa 414/2010 da Agência Nacional de Energia Elétrica(ANEEL), sendo uso periódico tempo de II h $52 \mathrm{~min}=11,87 \mathrm{~h}$ (ANEEL, 20Io), com o levantamento real da potência total instalada de todos os pontos de consumo da iluminação e considerando o custo unitário do $\mathrm{kWh}$ de $\mathrm{R}$ o,46 (RECIFE, 2015) se obteve o consumo total mensal de energia elétrica para cada tecnologia de iluminação (Tabela 2).

Tabela 2 - Consumo e gasto mensal de energia elétrica com tecnologia iluminação de lâmpadas de descarga elétrica de sódio (VS) e a LED.

\begin{tabular}{|c|c|c|c|c|c|c|c|c|}
\hline \multirow{2}{*}{$\begin{array}{l}\text { Tipo de } \\
\text { lâmpada }\end{array}$} & \multicolumn{2}{|c|}{ Potência(W) } & \multirow{2}{*}{$\begin{array}{l}\text { Tempo } \\
\text { (h) }\end{array}$} & \multirow{2}{*}{$\begin{array}{l}\text { Total } \\
\text { de } \\
\text { dias }\end{array}$} & \multirow{2}{*}{$\begin{array}{l}\text { Total de } \\
\text { lâmpadas }\end{array}$} & \multirow{2}{*}{$\begin{array}{l}\text { Consumo } \\
\text { mensal } \\
(\mathrm{kWh})\end{array}$} & \multirow{2}{*}{$\begin{array}{l}\text { Custo } \\
\mathrm{kWh} \\
(\mathrm{R} \$)\end{array}$} & \multirow{2}{*}{$\begin{array}{l}\text { Gasto } \\
\text { mensal } \\
(\mathrm{R} \$)\end{array}$} \\
\hline & $\begin{array}{l}\text { Sem } \\
\text { reator }\end{array}$ & $\begin{array}{l}\text { Com } \\
\text { reator }\end{array}$ & & & & & & \\
\hline LED & 200 & 200 & 11,87 & 30 & 419 & $29.841,18$ & 0,46 & $13.726,94$ \\
\hline LED & 230 & 230 & 11,87 & 30 & 96 & $7.862,69$ & 0,46 & $3.616,84$ \\
\hline $\begin{array}{l}\text { Vapor de } \\
\text { sódio }\end{array}$ & 250 & 274 & 11,87 & 30 & 628 & $61.274,84$ & 0,46 & $28.186,43$ \\
\hline
\end{tabular}

Fonte: elaborado pelo autor, (2019). 
Observa-se no Quadro 3, que a vida útil da luminária LED é mais do dobro da lâmpada de sódio. No caso em estudo, considerando o consumo anual, o consumo de energia das 628 lâmpadas de sódio é de $735.298,07 \mathrm{kWh}$, enquanto que as 515 luminárias LED apresentaram o consumo de $452.446,42 \mathrm{kWh}$. O gasto anual com energia elétrica com a lâmpada de sódio foi de $\mathrm{R} \$ 338.237$,II, enquanto que as luminárias LED foi $\mathrm{R} \$ 208.125,35$ resultando em uma economia de $\mathrm{R}$ \$30.III,76 que corresponde a uma redução de $38,47 \%$.

Quadro 3 - Comparativos luminária com lâmpada de sódio e luminária LED

\begin{tabular}{|l|c|c|}
\hline \multicolumn{1}{|c|}{ Tecnologia } & Anterior & Nova \\
\hline Variáveis & Lâmpada VS & Luminária LED \\
\hline Potência (W) & 250 & $200 / 230$ \\
\hline Quantidade & 628 & 515 \\
\hline Vida útil (h) & 22.000 & 50.000 \\
\hline Quantidade de postes & 157 & 288 \\
\hline Consumo anual (kWh) & $735.298,07$ & $452.446,42$ \\
\hline Gasto anual (R\$) & $338.237,11$ & $208.125,35$ \\
\hline $\begin{array}{l}\text { Economia energia com uso da nova tecnologia } \\
\text { (kWh) }\end{array}$ & $282.851,65$ \\
\hline Percentagem de economia em kWh (\%) & \multicolumn{2}{|c|}{38,47} \\
\hline Economia anual (R\$) & \multicolumn{2}{|c|}{$130.111,76$} \\
\hline Percentagem de economia R\$ (\%) & \multicolumn{2}{|c|}{37} \\
\hline
\end{tabular}

Fonte: elaborado pelo autor, (2019).

Verificação dos resíduos devido a substituição das lâmpadas VS por luminárias LED, para o estudo de caso, em função do seu tempo de vida útil (Tabela 3) relacionado com o tempo de uso (ANEEL, 2010) na base anual.

Tabela 3 - Lâmpadas de descarga elétrica e seus tempos de vida.

\begin{tabular}{|l|c|}
\hline \multicolumn{1}{|c|}{ Tipo de lâmpada } & $\begin{array}{c}\text { Vida útil em } \\
\text { (horas) }\end{array}$ \\
\hline Vapor de sódio de alta pressão & 15.000 a 24.000 \\
\hline Vapor metálico & $\mathbf{8 . 0 0 0}$ a 12.000 \\
\hline Vapor de mercúrio & 10.000 a 15.000 \\
\hline LED & 40.000 a 90.000 \\
\hline
\end{tabular}

Fonte: adaptado de BRASIL, (2018b).

A quantificação dos resíduos foi obtida de acordo com o seguinte procedimento: 
i) primeiramente, considerando as lâmpadas VS no caso em questão, cuja quantidade total = 628 unidades e durabilidade média (razão entre vida útil de 22.00o h e tempo de uso) = 5,15 anos; ii) após a substituição por luminárias LED, tem-se: luminárias LED, cuja quantidade total $=515$ unidades e durabilidade média (razão entre vida útil de 50.000 h e tempo de uso) = II,70 anos; iii) calculando-se a razão das durabilidades das luminárias LED e das lâmpadas VS consideradas, obtém-se que a razão entre as durabilidades médias $11,70: 5,15=2,27$; iv) verifica-se, portanto, que as luminárias LED duram em média 2,27 vezes mais que as lâmpadas a vapor de sódio; $v$ ) considerando-se agora o tempo de vida médio de uma luminária LED, calcula-se quantas lâmpadas de vapor de sódio seriam necessárias no mesmo período de tempo: para o tempo de II,70 anos total de lâmpadas de sódio = 2,27 x 628 = 1425,56; vi) a redução na quantidade de resíduos (lâmpadas a serem descartadas) no final deste período de II,70 anos: Resíduos $(\mathrm{R})$ da $\mathrm{LED}$ relativo à de sódio $\mathrm{R}=515: 1425,56=0,36=36 \%$

- Portanto para um mesmo tempo de uso dos sistemas de iluminação, redução para 36\% da quantidade de resíduos em relação as lâmpadas de sódio.

A estimativa da quantidade de emissão dióxido de carbono $\left(\mathrm{ECO}_{2}\right)$, para o presente estudo de caso, em função do consumo de Energia Elétrica Anual é obtida pela Equação (2) abaixo:

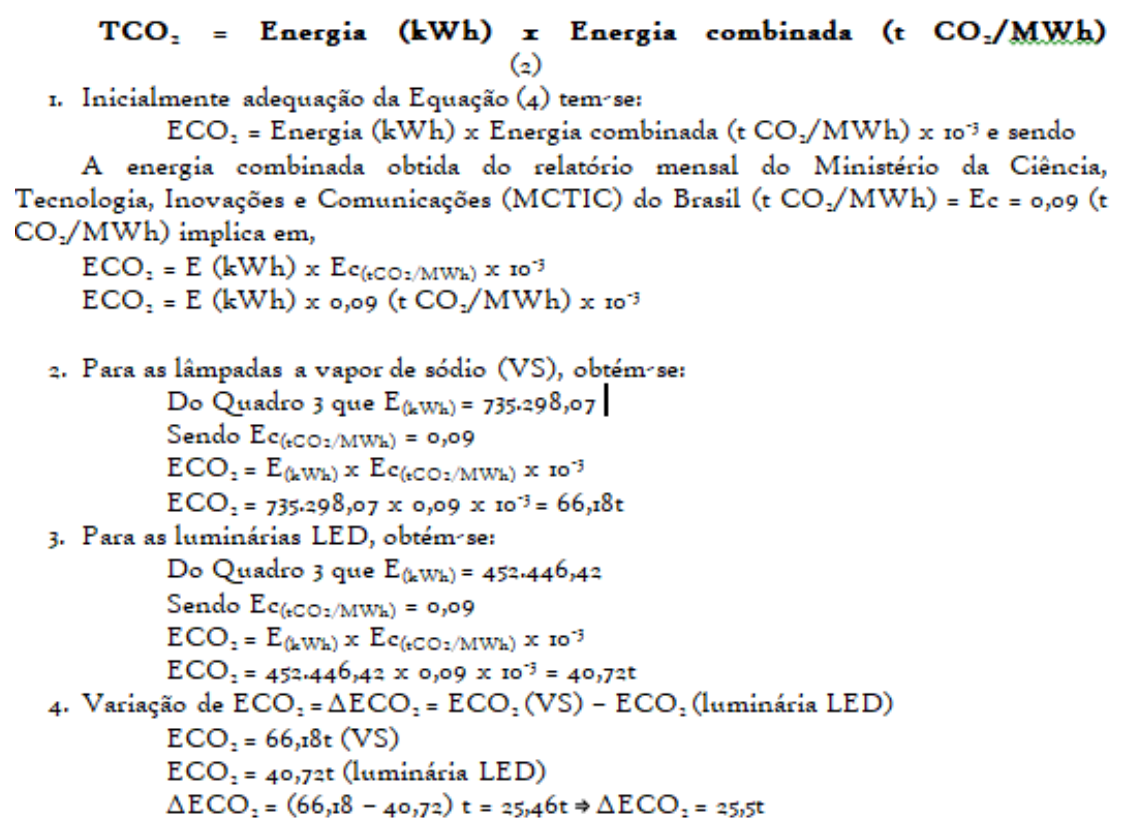


Levando-se em conta os dados que foram analisados, pode-se observar a significativa redução no impacto ambiental consequente da adoção da tecnologia de luminárias LED na iluminação pública.

\section{CONSIDERAÇÕES FINAIS}

Tendo em vista os aspectos observados neste trabalho, para o estudo de caso realizado da Avenida Recife, verifica-se a relevância dos meios que aumentem a eficiência energética das fontes de iluminação para redução das perdas, dos impactos ambientais e que levem à promoção de desenvolvimento sustentável.

Indicadores significativos e relevantes, obtidos como consequência da substituição das lâmpadas a vapor de sódio pela tecnologia LED, foram: $i$ ) comprovação da economia de energia para o local pesquisado de $282.851,65 \mathrm{kWh}$, por ano, o que representa uma diminuição de gasto anual para o município de $\mathrm{R} \$$ 130.III,76, ou seja, 38,47\%; ii) para um mesmo tempo de uso dos sistemas de iluminação, redução de 64\% da quantidade de resíduos das lâmpadas de sódio e redução da emissão de dióxido de carbono para 62\%.

Estes resultados demonstram como a tecnologia de iluminação LED se apresenta como uma alternativa ecologicamente mais sustentável para uso na iluminação pública. Nesse sentido, deixou claro a economia e a redução do impacto ambiental proporcionada por essa tecnologia em relação as lâmpadas de sódio, evidenciando ainda a necessidade do atendimento e verificação do acompanhamento criterioso as normativas e resoluções intervenientes existentes. Abre-se um novo paradigma para a iluminação pública (IP).

A ciência da iluminação se sobressai pela abrangência de diversas áreas de conhecimento. As inovações de eficiência energética com eliminação progressiva dos produtos de iluminação convencionais sob as regras de desempenho energético precisam ser consensuais na busca de soluções com a não agressão a saúde humana, ou de danos ambientais e à biodiversidade.

Desta verdadeira revolução tecnológica estará em primeiro plano como elemento de transformação as cidades conjuntamente com governo, indústria, organizações à sociedade civil e bancos de apoio ao desenvolvimento. As ações sendo projetadas adequadamente interferirão positivamente na redução da poluição ambiental, emissões negativas, segurança e elevação da qualidade de vida do povo. 
A experiência deste estudo de caso servirá de indicador para a replicação da tecnologia de iluminação LED noutros logradouros, como também, de elo integralizador de ações de contorno socioeconômico e ambiental que potencializarão outras áreas do saber e tecnológicas.

\section{REFERÊNCIAS}

AGUILAR, R.C.S. Destino de lâmpadas fluorescentes pós-consumo: estudo de caso em um estabelecimento de Governador Valadares - MG. 2015. Instituto Federal de Educação, Ciências e Tecnologia de Minas Gerais - IFMG: Governador Valadares, 2015. Disponível em: https://bit.ly/2Db7Hkr Acesso em: 29 jul. 2020.

ALVES, J. E. D. A dependência do consumo transforma a cidadania em doença consumista. EcoDebate, out, 2018. Disponível em: https://bityli.com/MZmox. Acesso em: I2 jan. 2019.

\section{ANEEL. AGÊNCIA NACIONAL DE ENERGIA ELÉTRICA. Resolução Normativa Nº} 4I4: estabelece as condições gerais de fornecimento de energia elétrica de forma atualizada e consolidada. Distrito Federal: ANEEL, 2oro, p. 42.

\section{ASSOCIAÇÃO BRASILEIRA DAS CONCESSIONÁRIAS DE ILUMINAÇÃO} PÚBLICA. ABCIP. Notícias. São Paulo: ABCIP, 2020. Disponível em: https://bityli.com/ThASZ. Acesso em: 23 jul. 2019.

AIE. AGÊNCIA INTERNACIONAL DE ENERGIA. World Energy Outlook 2or8: perspectivas energéticas globais a longo prazo. Rio de Janeiro: IEA, 2019. Disponível em: https://bityli.com/mX607. Acesso em: I2 jan. 2020.

BERGSTRÖM, L. et al. Blue LEDs: filling the world with new light. Royal Swedish Academy of Sciences, out. 2014. Disponível em: https://bityli.com/kfU7D. Acesso em: 20 nov. 2019 . 
BRASIL. [Constituição (1988)]. Constituição da República Federativa do Brasil de 1988. Brasília, DF: Presidência da República, [2016]a. Disponível em: http://www.planalto.gov.br/ccivil_03/constituicao/constituicao.htm. Acesso em: II fev. 2019.

BRASIL. Lei no 13.280, de 3 de maio de 2016. Altera a Lei no 9.991, de 24 de julho de 2000, para disciplinar a aplicação dos recursos destinados a programas de eficiência energética. Brasília, DF: 2016b. Disponível em: https://bityli.com/8pYV3. Acesso em: 28 fev. 2019.

BRASIL. Ministério de Minas e Energia. Anuário Estatístico de Energia Elétrica 2018. Brasil: EPE, 2018a. Disponível em: https://cutt.ly/GsfgkVo. Acesso em: o9 dez. 2019.

BRASIL. Ministério das Minas e Energia. Iluminação pública municipal- programas e políticas públicas: orientações para gestores municipais. Brasília, DF: Ministério das Minas e Energia, fev. 2018b. Disponível em: https://bityli.com/owTb5. Acesso em: ro jan. 2019.

DANTAS, O. de L.; APOLÔNIO, R.; JÚNIOR, A. A. Potencial da geração distribuída e seu impacto na redução de emissões de $\mathrm{CO}_{2}$ : Estudo de uma micro usina fotovoltaica conectada à rede de energia elétrica. Engevista, v. 2I, n.2, 2019. Disponível em: https://bityli.com/jOK5I. Acesso: 13 mai. 2019.

EMLURB. EMPRESA DE MANUTENÇÃO E LIMPEZA URBANA. [Correspondência]. Destinatário: Coordenadora do Mestrado Profissional do ITEP. Recife, 2020. I e-mail.

EMLURB. EMPRESA DE MANUTENÇÃO E LIMPEZA URBANA. Obra de requalificação da iluminação da av. Recife. Projeto básico. Recife: EMLURB, 2017. Disponível em: https://cutt.ly/tsUuzLi. Acesso em: 04 mai. 2019.

FERNANDES, A. L.; RASOTO, V. I. Estudo sobre a viabilidade econômica e impactos urbanos no uso de lâmpadas LED (diodo emissor de luz) na iluminação pública da cidade de 
Curitiba. Revista FAE. Curitiba, 2017. Disponível em: https://revistafae.fae.edu/revistafae/article/view/177. Acesso em: i5 abr. 2020.

GOMES, M. B. Proposta de um Roadmap para avaliação de riscos em projetos de perfuração direcional horizontal. 2016. Dissertação (Mestrado em Engenharia de Produção) Universidade Federal da Paraíba, João Pessoa. 2016. Disponível em: https://bityli.com/O5ME5. Acesso em: I fev. 2019.

GUSMÃO, S. Brasil inicia processo para instalação da logística reversa. Brasília: Ministério do Meio Ambiente, 2017. Disponível em: https://bit.ly/2Xg7dAE. Acesso em: 28 jul. 2020.

INTERNATIONAL ENERGY AGENCY. Global Energy \& $\mathrm{CO}_{2}$ Status Report 2017. Paris: IEA, 2017. Disponível em: https://bityli.com/JfZSJ.pdf. Acesso em: I5 jan. 2019.

KAZA, S. et al. O que é um desperdício 2.0: um instantâneo global da gestão de resíduos sólidos para 2050. Washington, DC: Banco Mundial, set. 2018. Disponível em: https://bityli.com/Nhnll. Acesso em: 15 out. 2019.

KRUGER, C.; RAMOS, L. F. Iluminação pública e eficientização energética. Revista Espaço Acadêmico, Maringá, v.ı, n. I85, out. 20I6. Disponível em: https://bityli.com/JHIfW. Acesso em: 27 set. 2019.

PINTO, M. A. C.; KIRCHNER, C. A. R. Cenário atual e oportunidades para atuação em Iluminação Pública no Brasil. Brasília: Federação Nacional dos Engenheiros, 2016. Disponível em: https://bityli.com/YwZW6. Acesso em: r jul. 2019.

PIRES, M. F. T. A Tecnologia LED na Iluminação Pública do Recife. Revista On-line IPOG, Recife, PE, v. I, n. 13, jul. 2017. Disponível em: https://bityli.com/q92Sg. Acesso em: 20 dez. 2018. 
PROCEL. Programa Nacional de Conservação de Energia. PROCEL. Resultados 2018 ano base 2017. Brasil: PROCEL, 2018. Disponível em: https://bityli.com/SKzYM. Acesso em: I2 jan. 2019.

RECIFE. Prefeitura Municipal. Decreto no 28.771 de 27 de abril de 2015. Regulamenta os procedimentos concernente à Contribuição para Custeio da Iluminação Pública. Recife: Sistema de Leis Municipais, 2018.

SANTOS, E. R. dos. A Iluminação pública como elemento de composição da paisagem urbana. 2005. Dissertação (Mestrado em Arquitetura) - Universidade Federal do Rio Grande do Sul, Curitiba, 2005. Disponível em: https://bit.ly/3j2gHYw. Acesso em:19 ago.202o.

SANTOS, R. A. dos et al. Procedimentos de segurança para o manuseio correto e consciente de lâmpadas de vapor. Revista Teccen, Universidade Severino Sombra - USS, Vassouras RJ, Brasil, out. 2017. Disponível em: https://bityli.com/E8VCt. Acesso em: 23 dez. 2018. 